\title{
The power of attention
}

\author{
Lucía Jiménez $^{a}$ \\ ${ }^{\mathrm{a}}$ Feel in Flow Coaching, Spain.
}

\section{ABSTRACT}

This article attempts to define the concept of attention and characterise its main characteristics in order to better its impact during the learning process as well as on the tennis player's own performance. This is accompanied by examples of exercises as well as guidelines for the improvement of this crucial psychological ability, on and off court.
Key words: Focus, concentration, full attention, learning, emotion.

Received: 03 March 2020

Accepted: 23 March 2020 Corresponding author: Lucía Jiménez, Feel in Flow Coaching, Spain. Email: lucia@feelinflow.com

\section{INTRODUCTION}

'Attention' as an umbrella term incorporates several terms which although related, are different to each other and have different connotations that should be considered. What is certain is that this mental aspect belongs to a large family of concepts named 'attention skills', and that classification of a player with reference to these different skills provides us with information about the tennis player's ability to function and progress in his/her learning process, from recreational levels to competitive ones. The concepts that emerge from the study of attention, as well as the one that we mainly deal with in this article bring to mind a whole host of situations that are transmitted and take place on-court. We will look at how to use and train attention in a way that helps improve the performance of our players.

"I was playing pretty well in the first set until 5-2. Maybe I thought too early on that the match was over. I lost my concentration for just one game, and the match turned completely"(Justin Henin)

Of the multiple definitions of attention, Reategui (1999) explains it as follows: "attention is a discriminatory and complex process that accompanies all cognitive processing, it is also responsible for filtering information and allocating resources to allow internal adaptation of the organism in relation to external demands".

In other words, attention, being discriminatory, is partially voluntary or intentional, as it allows the mind to attend to one thing or another based on interest/motivation, objectives, relevance, etc. On the other hand, it is complex and accompanies the entire cognitive process which includes the processes of decision-making, memory, and (very relevantly for the context of this paper) emotional regulation. Finally, it is responsible for filtering the information which in turn allows for the allocation of resources that make it possible to adapt to the incoming ball or situation. That said, and transferring this definition to tennis, the attention we develop while playing allows us to attend to one or the other stimuli depending on our interest, i.e. do I focus on how the ball just hit is coming to me, or do I stay focused on the previous failure and focus my attention on the circumstances that led to it? In addition, this attention will condition a player to either play aggressively, looking for the next point, or more conservatively. It will also remind a player - consciously and unconsciously - of the situations in which that same situation has happened to them in previous games, and finally, depending on how constructive the interpretation they make of it (on how I say it to myself), it makes the player feel better or worse, guiding their resolve in one direction or another.

In short, attention is the precursor, the seed or crucial point of how games develop in many cases or of a learner progressing faster or slower in their learning process. It is not by chance that the prestigious psychologist and journalist of the wellknown Emotional Intelligence concept, Daniel Goleman, dedicated his next book 'Focus' (2003) to this great protagonist of our tennis life - "attention".

TYPES OF ATTENTION AND THEIR RESPECTIVE APPLICATIONS IN LEARNING IN TENNIS

From the different classifications available, the following are the most relevant for the current context:

a) Based on the mechanisms involved: 
Selective or focused attention: Defined as the player's ability to select the relevant stimuli and discard those that are not. Example: The player who is attentive to his score regardless of how the courts next to him/her are doing. This involves being able to continue paying attention to the dynamics of the game despite the distractions that the other player performs, i.e. his/her possible complaints, celebrations, and signs of pain due to possible injury.

Divided attention: Ability to pay attention to several stimuli at the same time. It is known that we can effectively attend to two stimuli when one of them is automated; it is therefore a matter of distributing attention resources effectively. Examples: a player focuses on the place where he wants to serve without having to think about how he is going to hit the ball; or, a player has a game plan for the next point and is able to observe where the other player is located as he is about to hit the ball, thus being able to change the initial plan.

Sustained Attention: Ability to keep attention on relevant stimuli for a desired amount of time. A lot of time, this is referred to as concentration. The obvious example is being able to stay focused throughout the entire game, without large absences in attention, that are normally natural.

\section{b) Based on the object to which it is directed:}

External Attention: We attend to external stimuli such as: the ball, the court, contact point, and the non-dominant hand... any object external to oneself.

Internal Attention: Stimuli from our bodily sensations and that are closely related to everything we perceive through the body. For example: feeling on the grip, focusing on the breath, the position of my shoulders when taking off or walking, the support of the feet, the sound of the ball when I hit...

\section{EXERCISES TO IMPROVE DIFFERENT TYPES OF} ATTENTION:

\section{Selective Attention:}

1. Pay Attention!: The coach feeds balls to the player with the hand or with a racket. The player has to follow certain tactical guidelines for the directions to aim for depending on the type of incoming ball (attack, defensive, construction). Meanwhile, another player speaks to the one playing, from behind, trying to distract him.

2. Deaf Ears: Players play a set with music playing on speakers. The guideline to the players will be to focus on the tasks proposed for the set, without paying attention to the music. At the end of the set the player will reflect on how many songs they remember. The more they remember, the less selective capacity they will have shown.
3. Listen...: Sitting near the training court, the player or players close their eyes and is invited to pay attention to the sounds of the environment, e.g. birds, wind, cars, people, the sound of the other hitting the ball, a coach making a comment, etc.. After a few minutes you are asked to focus only on one of them and try, at the end of the exercise, to describe it in depth, with as much nuance as possible.

Divided Attention:

4. Getting Dizzy: A cooperative rally is carried out with a partner: They rally cross-court, and when player A sees an opportunity, hits down-the-line and the sequence continues. At the same time, partner " $C$ ", placed behind " $B$ ", will do different individual balance or agility exercises. At the end, player "A" will name the exercises performed by player " $C$ " of which he has been aware. NOTE: The objective will only have been achieved if the rally between players $A$ and $B$ has been of a high quality.

5. Surprise: Two players rally together cooperatively down the line or cross-court; When the coach sees fit, he will put another ball into play so that the players forget about the rally ball and continue to play the point with the "new" ball.

6. Hawk-eye: The players sit down next to the training sessions of three different courts, they are given the following guideline: "You have 3 minutes to observe the three courts". Afterwards, the players reflect on who trains on each court and what exercise they are doing?

Sustained Attention:

7. Am I here or not?: A tie-break is played and at the end of it the player will write down the thoughts that have crossed his mind, and whether these are directed to the past, present or future.

8. Super Focus: Perform "your" ritual after each point for the next 20 minutes. How many points have you not done it for?

9. Am I or not II?: Close your eyes and keep your mind blank for a minute. How many times have you "drifted" from this? In this exercise we are not intending for the player to spend the whole minute with a blank mind, this would show a very high level of concentration that requires years of practice; the point of the exercise is to teach the player to "return" to their mental screen whenever they drift, teaching awareness that they can return whenever they choose. Over time, the length that one can stay 'blank' may be increased. 


\section{ATTENTION AND ADOLESCENCE: LEARNING OPPORTUNITIES}

Today, teenagers as well as children have an increased ability to pay attention to multiple stimuli at once; Digitalisation has caused the general pace of life to increase enormously whilst causing waiting times and patience to decrease, with this last virtue even losing value for younger generations. In this sense, tennis is currently immersed in one of its great battles, the one that marks "the society of immediacy vs. learning processes". This trend has even influenced tennis regulations: matches with 4 games, super tie-breaks in the third set, no-let net rule, golden ball; however, not all of these situations are actually that inconvenient or difficult, and as with any other situations that occurs when we play, we can use these circumstances to improve. On the one hand, the young tennis player's high capacity to switch attention to various stimuli allows him to receive more information that when well selected and organized, stimulates a greater capacity for assimilation. This is all accompanied of course by training with sustained attention, concentration, as well as attention to the present moment (mindfulness), as proposed by Van de Braam and Aherne (2016) or Yousuf (2016). For this, Tennis is an ideal setting, given that a tennis point in itself grounds you in the present moment naturally, since the ball always returns and never in the same way, necessitating conscious and unconscious adjustments constantly.

On the other hand, the speed at which the matches are played, with the rules that have been implemented (especially in lower categories), put the player to the test in handling emotionally charged situations much more frequently and quickly; thus, they become potentially expert regulators of stress, when and if, of course they are accompanied and guided in the process.

Guidelines for improving attention skills:

We know that there are certain stimuli that attract our attention more than others, therefore, we use this information and apply it to the exercises that we propose. Taking into account the variables that Roselló (1998) proposes, at the level of external stimuli, we find:

1. Novelty: Present different exercises or variants on exercises which you already use

2. Complexity: When we don't master something, our attention is focused on capturing it, trying it, failing, restructuring and trying again.

3. Intensity: The same exercise with a different intensity, either slower or faster, makes us pay a different type attention to before.

4. Repetition: Whilst repetition creates monotony and can decrease motivation, it is, especially in advanced players, a great tool to develop attention since tennis players often face repetition in their careers (e.g. first rounds, matches with a lot of rallies, heavy balls and therefore difficulty in closing points ...).

5. Color, movement, position: This will consist of introducing variables in the exercises that we usually do, taking these aspects into account.

Table 1: Guidelines for developing attention

\section{ENEMIES OF ATTENTION}

Although improving attention requires willingness and intention, there are certain variables that affect it and that, if unknown, can confuse us about what may actually be failing in the process. We may think that our player has certain technical deficiencies or difficulties in learning, but what may be happening is something different related to the following (Czajkowski, 1996):

1. Tiredness: When we are tired, we lower our defenses at all levels, the most evident being at the physical level. We should also be aware that this also affects our emotions (we get irritated more easily, we have less patience) as well as with our cognitive capacity, in this case the difficulty to keep our attention on the stimulus that interests us.

2. Boredom: This is a double-edged sword because, although it diminishes the attentional capacity (the mind jumps from one thought to another randomly, without apparent control), we should not always run away from it since it constitutes a great space to develop creativity, as well as to improve attentional capacity, as long as the players knows how to transcend the subjective feeling of "boredom".

3. Low activation: A low activation puts the brain at a rate of work at odds with our most effective attentional peak; therefore, 'activation' is a great mechanism to return attention to what interests us

\section{CONCLUSION}

Attention has been a concept widely recognized in sports psychology for many years. While in recent times the rise of Emotional Intelligence has shifted this crucially important cognitive ability from the main focus, the popularity of Mindfulness has once again highlighted its importance. Given the importance of attention, seen in the multiple tennis situations-mentioned during this article in which the it plays a large role, it seems logical to train it with the same intensity or importance given to other psychological technical-tactical and physical skills. Furthermore, remembering that every situation is an opportunity to improve attention, it is not the same to do physical training whilst thinking of things that have little to do with training, than to do the same exercise focusing on range of motion and/or muscles involved; just as hitting balls is not the same as paying attention to them with a specific intention.

\section{REFERENCES}

Czajkowski, Z. (1996) Psychology as a coach's aid. Centralny Ośrodek Sportu, Warszawa.

Goleman, D. (2013). Focus. Barcelona: Kairós.

Reategui, N y Sattler, C. (1999). Metacognición. Estrategias 
para la construcción del conocimiento. (2da. Ed.) Lima: CEDUM

Roselló, J. (1996). Psicología de la Atención. Madrid: Pirámide. Van de Braam, M. y Aherne, C. (2016). Mindfulness: Applications in tennis. ITF Coaching and Sport Science Review, 70, 3-4.

Yousuf, S. (2016). Mindfulness and tennis performance: A review of literature and practice. ITF Coaching and Sport Science Review, 70, 13-14.

RECOMMENDED ITF TENNIS ACADEMY CONTENT (CLICK BELOW)

\section{ITF Academy}

Copyright (c) 2020 Lucía Jiménez

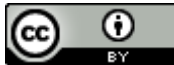

This text is under a Creative Commons BY 4.0 license

You are free to Share - copy and redistribute the material in any medium or format - and Adapt the content - remix, transform, and build upon the material for any purpose, even commercially under the following terms:

Attribution: You must give appropriate credit, provide a link to the license, and indicate if changes were made. You may do so in any reasonable manner, but not in any way that suggests the licensor endorses you or your use. 